\title{
Rural and Urban Living in Persons with Spinal Cord Injury and Comparing Environmental Barriers, Their Health, and Quality-of-Life Outcomes
}

\author{
R. Andrew Glennie, Juliet Batke, Nader Fallah, Christiana L. Cheng, Carly S. Rivers, \\ Vanessa K. Noonan, ${ }^{3}$ Marcel F. Dvorak, Charles G. Fisher, Brian K. Kwon, and John T. Street ${ }^{2}$
}

\begin{abstract}
There is worldwide geographic variation in the epidemiology of traumatic spinal cord injury (tSCI). The aim of this study was to determine whether environmental barriers, health status, and quality-of-life outcomes differ between patients with tSCI living in rural or urban settings, and whether patients move from rural to urban settings after tSCI. A cohort review of the Rick Hansen SCI Registry (RHSCIR) was undertaken from 2004 to 2012 for one province in Canada. Rural/urban setting was determined using postal codes. Outcomes data at 1 year in the community included the Short Form-36 Version 2 (SF36v2 ${ }^{\mathrm{TM}}$ ), Life Satisfaction Questionnaire, Craig Hospital Inventory of Environmental Factors-Short Form (CHIEFSF), Functional Independent Measure ${ }^{\circledR}$ Instrument, and SCI Health Questionnaire. Statistical methodologies used were $t$ test, Mann-Whitney U test, and Fisher's exact or $\chi^{2}$ test. In the analysis, 338 RHSCIR participants were included; 65 lived in a rural setting and 273 in an urban setting. Of the original patients residing in a rural area at discharge, 10 moved to an urban area by 1 year. Those who moved from a rural to urban area reported a lower SF-36v2 $2^{\mathrm{TM}}$ Mental Component Score (MCS; $p=0.04)$ and a higher incidence of depression at 1 year $(p=0.04)$. Urban patients also reported a higher incidence of depression $(p=0.02)$ and a lower CHIEF-SF total score $(p=0.01)$ indicating fewer environmental barriers. No significant differences were found in other outcomes. Results suggest that although the patient outcomes are similar, some patients move from rural to urban settings after tSCI. Future efforts should target screening mental health problems early, especially in urban settings.
\end{abstract}

Keywords: community needs; follow-up studies; quality of life; rural urban migration; spinal cord injury

\section{Introduction}

Q PINAL CORD INJURY (SCI) is a devastating injury that affects $\checkmark$ roughly 4100 Canadians each year and can have profound, long lasting consequences on how an individual proceeds with daily life. ${ }^{1}$ The majority of the Canadian urban population is concentrated in larger metropolitan areas along the southern border, with a smaller portion living in the vast northern rural areas of the country. Activities that are more commonplace in rural areas include forestry, mining, skiing, snowmobiling, and mountain biking, and these are all associated with traumatic spinal cord injury (tSCI), potentially leading to a greater proportion of injuries in rural ha- bitants. It has been reported that residents of rural areas are at twice the risk of accidental injury compared with those in urban areas. ${ }^{2}$

Despite an overall increase in the population of the province of British Columbia, the rural population has declined due to low birth rates and migration of youth to urban areas. ${ }^{3}$ It is also likely that individuals at higher risk for medical complications and mortality, such as those with tSCI, migrate to urban regions to be closer to medical facilities. ${ }^{4}$ Previous reports have evaluated the differences in patient outcomes in various other chronic illnesses, such as chronic obstructive pulmonary disease and congestive heart failure, when comparing rural and urban patients, but this has been challenging in tSCI due to the rarity of the condition. ${ }^{5-7}$

\footnotetext{
${ }^{1}$ Department of Surgery, Dalhousie University, Halifax, Nova Scotia, Canada.

${ }^{2}$ Vancouver Spine Surgery Institute, Department of Orthopaedics, University of British Columbia, Vancouver, British Columbia, Canada.

${ }^{3}$ Rick Hansen Institute, Vancouver, British Columbia, Canada.
}

(c) R. Andrew Glennie et al., 2017; Published by Mary Ann Liebert, Inc. This Open Access article is distributed under the terms of the Creative Commons Attribution Noncommercial License (http://creativecommons.org/licenses/by-nc/4.0/) which permits any noncommercial use, distribution, and reproduction in any medium, provided the original author(s) and the source are credited. 
The acute and subsequent treatment of individuals suffering from tSCI requires the collaborative efforts of multiple healthcare professionals. Specialized and focused care is provided at large tertiary referral centers for the acute and rehabilitation phases of tSCI. ${ }^{8-11}$ Due to the number of potential secondary health conditions that may arise in the long-term follow-up of individuals with tSCI, providing comprehensive care may be challenging, especially for family practitioners in remote locations. ${ }^{12}$ Rehospitalization of patients with longstanding tetraplegia or paraplegia may occur for numerous reasons; Dryden and colleagues have reported that over the 6 years following an SCI, $44.1 \%$ of individuals were rehospitalized for urinary tract infections, pressure ulcers, pneumonia, or septicemia, $33.3 \%$ of whom had multiple health conditions. ${ }^{13}$ Others have reported that in the first year following SCI, $36.2 \%$ of individuals with SCI are hospitalized at least once, and $12.5 \%$ are hospitalized twice or more. ${ }^{14}$ These associated conditions not only increase the burden on the healthcare system, but also impact the individual's outcomes such as quality of life, well-being, and participation in the community. Further, environmental barriers have also been shown to have an impact on health status, ${ }^{15}$ social participation, ${ }^{16}$ and quality of life. ${ }^{17}$ It is unclear whether individuals with tSCI in rural areas would experience higher rates of secondary health conditions or environmental barriers, or how their rural residency affects their outcomes, including quality of life.

The goals of this study were to: 1) compare the environmental barriers experienced by individuals with tSCI, and the health and quality-of-life outcomes of those who live in rural versus urban settings at 1 year in the community; 2) determine how many individuals with tSCI moved from a rural to an urban setting after 1 year in the community; and 3) compare the patient outcomes between individuals who remained in rural setting with those who moved from a rural to an urban setting.

\section{Methods}

\section{Study design}

This cohort review utilized data from the Rick Hansen Spinal Cord Injury Registry (RHSCIR) collected from patients admitted to an SCI specialized acute care facility located within a Level I trauma center (Vancouver General Hospital) between 2004 and 2012. RHSCIR is a pan-Canadian prospective registry of patients with tSCI admitted to 1 of 18 acute and 13 rehabilitation facilities. All participating facilities obtained local research ethics approval before enrolling patients. A core dataset was collected for all patients, and an expanded dataset and a long-term community followup questionnaire administered over an extended period of time post-injury were collected for those who provided informed consent. ${ }^{18}$ Details of the RHSCIR and the community follow-up questionnaire are described elsewhere. ${ }^{18,19}$ For this study, community follow-up data collected between 9 and 18 months post-discharge from inpatient care (referred to as " 1 year in the community") were included in the analysis.

\section{Study variables}

Patient and injury factors. Demographic details of patients obtained from the RHSCIR expanded dataset used in the analysis were: age at injury, gender, education level, employment status, marital status, compensation status, neurological injury severity by American Spinal Injury Association (ASIA Impairment Scale [AIS]; AIS A, B, C, D, E), and neurological injury level (cervical, $\mathrm{C} 1-\mathrm{C} 8$; thoracolumbar, $\mathrm{T} 1$ and below) at discharge from inpatient care, both derived from the International Standards for Neurological Classification of SCI (ISNCSCI) examination. ${ }^{20}$

Rural and urban setting. The residential postal code collected at discharge from inpatient care and at 1 year in the community were used to determine living setting (rural vs. urban) at the respective time-points. Statistics Canada generally defines rural as being fewer than 400 people per square kilometer. The process of defining a rural or urban place of residence has been described previously. ${ }^{21}$ Individuals who migrated from one living setting to another between discharge and 1 year in the community were identified and compared with those who remained in the same living setting.

Outcomes. Patient outcomes analyzed in this study were collected in follow-up questionnaires and included: the Craig Hospital Inventory of Environmental Factors Short Form (CHIEF$\mathrm{SF}),{ }^{22}$ the Functional Independence Measure $\left(\mathrm{FIM}^{\circledR}\right)$ instrument, the Medical Outcomes Study 36-Item Short Form-36 Version 2 $\left(\mathrm{SF} 36 \mathrm{v} 2^{\mathrm{TM}}\right)$ Questionnaire, ${ }^{23}$ the Life Satisfaction Questionnaire (LiSat-11), and the SCI Health Questionnaire (SCIHQ). ${ }^{19}$ These outcome measures have been previously validated and shown to be appropriate with long-term follow-up of tSCI patients. ${ }^{19,22,25-27}$ The CHIEF-SF questionnaire measures the frequency and magnitude of perceived environmental barriers on participation in activities. A mean total CHIEF-SF score and the mean five subscale scores (policy barriers, physical/structural barriers, work/school barriers, attitudes/support barriers, and services/assistance barriers) were calculated. ${ }^{22}$ The FIM instrument was used to quantify physical and cognitive functioning, and a mean total FIM score was calculated. ${ }^{25}$ The SF36v2 assesses health status and includes eight domains (physical functioning, role limitations-physical, bodily pain, general health, vitality, social functioning, role limitationsemotional, mental health), which can be reported as Physical Component Score (PCS) and Mental Component Score (MCS). ${ }^{23}$ The LiSat-11 is a measure of quality of life, also referred to as subjective well-being, and a mean total score was calcuated. ${ }^{24}$ The SCIHQ asked the patient to self-report any secondary health conditions experienced, and the conditions selected for this study were deemed to require specialized care based on clinical expert opinion, and included: autonomic dysreflexia, deep vein thrombosis, depression, pressure ulcers, spasticity, and urinary tract infections. ${ }^{19}$

\section{Statistical analysis}

Descriptive statistics were used to describe demographic and injury factors of patients in the study cohort. Statistical tests were performed to compare patient outcomes between the rural and urban populations at 1 year in the community. After reviewing the distribution of data, normally distributed data were compared using $t$ test; data not normally distributed were compared using Mann-Whitney $\mathrm{U}$ test. For discrete data, Fisher's exact test or $\chi^{2}$ test was used.

A sensitivity analysis was performed to test if patients lost to follow-up were different from those included in the study. A $p$ value of $<0.05$ was considered as significant. All statistical analyses were performed using IBM SPSS Statistics for Windows, Version 23.0 (IBM Corp., Armonk, NY).

\section{Results}

Of the 338 patients who completed the follow-up questionnaire and provided postal code data, 75 lived in rural and 263 lived in urban settings at the time of discharge. By 1 year in the community, 10 had moved from a rural to an urban setting, leaving 65 patients in rural and 273 in urban settings (Fig. 1). Table 1 describes the demographic and injury characteristics of patients by their living setting at discharge. The average ages for rural and urban patients were $42.7 \pm 17.8$ and $44.7 \pm 18.7$ years, respectively. There were no 
significant differences in age, gender, employment status, education level, or marital status between patients living in rural and urban settings (Table 1). There were also no significant differences in mechanism of injury or neurological injury severity (AIS) or level when comparing rural and urban patients (Table 1).

There was no difference in gender, employment, education, marital status, or neurological injury severity (AIS) or level between those who remained in a rural setting versus those who moved from a rural to urban setting. There was a marginally significant trend for those remaining in rural settings to be older ( 45.1 vs. 37.2 years, $p=0.05)$. Compensation type was similar between the group that remained in a rural setting (none $=39 \%$, disability/other $=30 \%$, vehicle/workers $=31 \%$ ) and those who moved from a rural to urban setting (none $=30 \%$, disability $/$ other $=40 \%$, vehicle $/$ workers $=30 \%$ ).

Patients who were lost to follow-up were significantly younger (39.1 vs. 44.1, $p=0.01$ ), more likely to have more severe injuries (AIS A/B/C) $(72 \%$ vs. $58 \%, p=0.02)$, and more likely to have cervical injuries $(67 \%$ vs. $50 \%, p=0.02)$ at time of discharge than those who responded to the follow-up questionnaire.

\section{Patient outcomes in rural and urban settings}

Patients living in rural settings at 1 year had a significantly higher mean CHIEF-SF total score compared with those living in urban $(1.3 \pm 0.9$ vs. $1.0 \pm 1.1, p=0.01)$, indicating more environmental barriers perceived by those living in rural settings. When comparing the subscales of the CHIEF-SF, patients living in rural settings reported a significantly higher score for the physical/ structural $(2.5 \pm 1.6$ vs. $1.7 \pm 1.9, p=0.002)$ and the services/assistance subscales $(1.7 \pm 1.5$ vs. $1.2 \pm 1.5, p=0.04)$ than the urban population (Table 2). There were no significant differences in the SF36v2 PCS and MCS, the FIM, or LiSat-11 total scores when comparing patients residing in rural and those in urban settings at 1 year (Table 2).

When comparing the subpopulation of patients who migrated from rural to urban and those who remained in rural settings, the migrants had significantly lower SF36v2 MCS than those who remained $(46.0 \pm 9.0$ vs. $53.4 \pm 10.1, p=0.04)$. CHIEF-SF total or

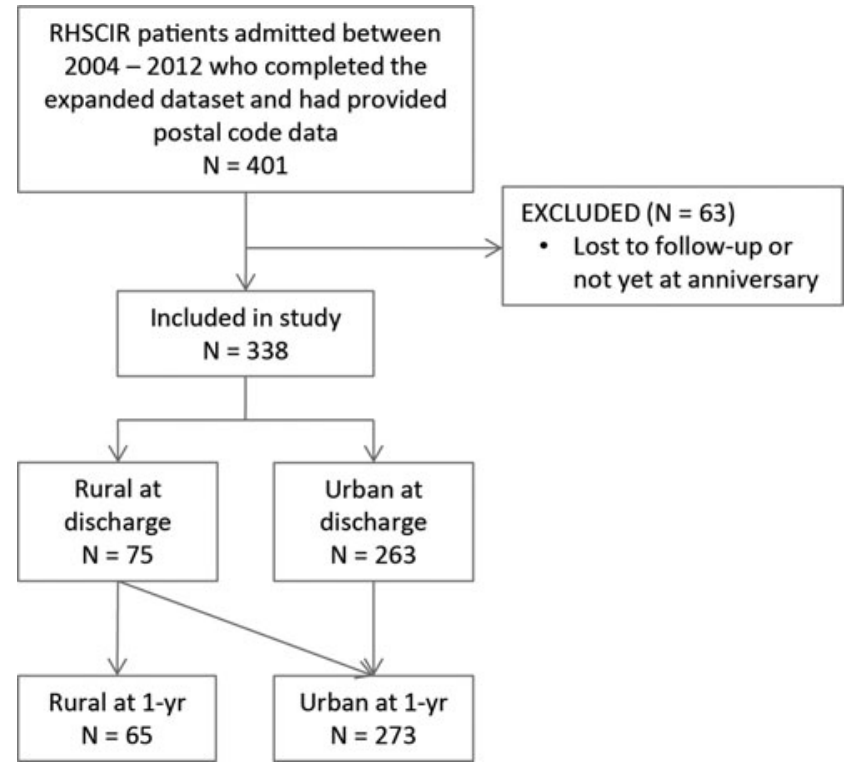

FIG. 1. Sample size flow chart for the study analysis. RHSCIR, Rick Hansen Spinal Cord Injury Registry.
Table 1. Patient Characteristics in the Cohort Study

\begin{tabular}{|c|c|c|c|}
\hline \multirow[b]{2}{*}{ Variable } & \multicolumn{3}{|c|}{ Living setting at discharge } \\
\hline & $\begin{array}{c}\text { Rural } \\
(\mathrm{n}=75)\end{array}$ & $\begin{array}{c}\text { Urban } \\
(\mathrm{n}=263)\end{array}$ & $\mathrm{p}$ value \\
\hline Age at injury, mean $\pm S D$ & $42.7 \pm 17.8$ & $44.7 \pm 18.7$ & 0.410 \\
\hline Male gender, n (\%) & $58(77.3 \%)$ & $182(77.1 \%)$ & 0.969 \\
\hline Employed (yes), n (\%) & $48(64.0 \%)$ & $158(68.4 \%)$ & 0.480 \\
\hline Education, n (\%) & & & 0.172 \\
\hline Less than high school & $22(29.3 \%)$ & $45(19.4 \%)$ & \\
\hline High school or higher & $53(70.7 \%)$ & $187(80.6 \%)$ & \\
\hline Marital status, n (\%) & & & 0.286 \\
\hline Married/Common law & $33(44.0 \%)$ & $118(51.1 \%)$ & \\
\hline Not married & $42(56.0 \%)$ & $113(48.9 \%)$ & \\
\hline Mechanism of injury, $\mathrm{n}(\%)$ & & & 0.221 \\
\hline Falls & $25(33.8 \%)$ & $85(38.8 \%)$ & \\
\hline Transport & $25(33.8 \%)$ & $63(28.8 \%)$ & \\
\hline Sports & $21(28.4 \%)$ & $48(21.9 \%)$ & \\
\hline Other & $3(4.1 \%)$ & $23(10.5 \%)$ & \\
\hline $\begin{array}{l}\text { ASIA Impairment } \\
\text { Scale (AIS), n (\%) }\end{array}$ & & & 0.280 \\
\hline AIS A/B/C & $46(61.3 \%)$ & $123(54.2 \%)$ & \\
\hline AIS D/E & $29(38.7 \%)$ & $104(45.8 \%)$ & \\
\hline $\begin{array}{c}\text { Neurological level of } \\
\text { injury, } n(\%)\end{array}$ & & & 0.221 \\
\hline Cervical (C1-C8) & $26(47.3 \%)$ & $88(51.8 \%)$ & \\
\hline $\begin{array}{l}\text { Thoracolumbar } \\
\text { (T1 and below) }\end{array}$ & $29(52.7 \%)$ & $82(48.2 \%)$ & \\
\hline
\end{tabular}

ASIA, American Spinal Injury Association; SD, standard deviation.

subscales, FIM, SF36v2 PCS, and LiSat-11 scores were not significantly different between these two populations (Table 3 ). In our dataset, no patients migrated from an urban to a rural setting.

\section{SCI secondary health conditions}

Of the secondary health conditions analyzed, only self-reported depression was significantly different between the patients living in

Table 2. Patient Outcomes at 1 Year in the Community Between Rural and Urban Populations

\begin{tabular}{lccc}
\hline Outcome; mean $\pm S D$ & $\begin{array}{c}\text { Rural } \\
(\mathrm{n}=65)\end{array}$ & $\begin{array}{c}\text { Urban } \\
(\mathrm{n}=273)\end{array}$ & p value \\
\hline CHIEF-SF & & & \\
$\quad$ Policies & $0.96 \pm 1.29$ & $0.88 \pm 1.58$ & 0.108 \\
$\quad$ Physical/Structural & $2.49 \pm 1.64$ & $1.71 \pm 1.92$ & $\mathbf{0 . 0 0 2}$ \\
Work/School & $0.32 \pm 1.09$ & $0.17 \pm 0.68$ & 0.361 \\
Attitudes/Support & $0.69 \pm 1.08$ & $0.70 \pm 1.45$ & 0.240 \\
$\quad$ Services/Assistance & $1.65 \pm 1.52$ & $1.23 \pm 1.50$ & $\mathbf{0 . 0 4 2}$ \\
$\quad$ Total score & $1.29 \pm 0.92$ & $0.98 \pm 1.06$ & $\mathbf{0 . 0 0 9}$ \\
Total FIM score & $100.14 \pm 24.54$ & $101.77 \pm 24.79$ & 0.704 \\
SF36v2 Physical & $31.11 \pm 10.40$ & $32.26 \pm 9.31$ & 0.432 \\
$\quad$ Component score & & & \\
SF36v2 Mental & $53.42 \pm 10.14$ & $50.59 \pm 12.34$ & 0.126 \\
$\quad$ Component score & & & \\
LiSat-11 total score & $3.98 \pm 0.89$ & $3.89 \pm 0.96$ & 0.573 \\
\hline
\end{tabular}

Bold $\mathrm{p}$ values denote statistical significance.

CHIEF-SF, Craig Hospital Inventory of Environmental Factors-Short Form; FIM, Functional Independence Measure; LiSat-11, Life Satisfaction Questionnaire; SD, standard deviation; SF36v2, Short Form-36 Version 2. 
Table 3. Patient Outcomes at 1 Year in the Community between Patients Who Stayed in a Rural Setting and Those Who Moved From a Rural to AN URban SETting

\begin{tabular}{lccc}
\hline & $\begin{array}{c}\text { Remained } \\
\text { in rural } \\
(\mathrm{n}=65)\end{array}$ & $\begin{array}{c}\text { Migrated } \\
\text { to urban } \\
(\mathrm{n}=10)\end{array}$ & $\mathrm{p}$ value \\
Outcome; mean $\pm S D$ & & & \\
\hline CHIEF-SF & $0.96 \pm 1.29$ & $0.75 \pm 1.31$ & 0.428 \\
$\quad$ Policies & $2.49 \pm 1.64$ & $2.56 \pm 2.34$ & 0.822 \\
Physical/Structural & $0.32 \pm 1.09$ & $0.31 \pm 0.70$ & 0.640 \\
$\quad$ Work/School & $0.69 \pm 1.08$ & $1.06 \pm 2.43$ & 0.626 \\
$\quad$ Attitudes/Support & $1.65 \pm 1.52$ & $1.56 \pm 1.41$ & 0.974 \\
$\quad$ Services/Assistance & $1.29 \pm 0.92$ & $1.30 \pm 1.28$ & 0.748 \\
$\quad$ Total score & $100.14 \pm 24.54$ & $96.30 \pm 21.90$ & 0.387 \\
Total FIM score & $31.11 \pm 10.40$ & $28.79 \pm 7.69$ & 0.505 \\
SF36v2 Physical & & & \\
$\quad$ Component score & $53.42 \pm 10.14$ & $45.99 \pm 8.99$ & $\mathbf{0 . 0 3 5}$ \\
SF36v2 Mental & & & \\
$\quad$ Component score & $3.98 \pm 0.89$ & $3.60 \pm 0.78$ & 0.223 \\
LiSat-11 total score & 3.96 \\
\hline
\end{tabular}

Bold $\mathrm{p}$ values denote statistical significance.

CHIEF-SF, Craig Hospital Inventory of Environmental Factors-Short Form; FIM, Functional Independence Measure; LiSat-11, Life Satisfaction Questionnaire; SD, standard deviation; SF36v2, Short Form-36 Version 2.

a rural and urban setting. Significantly more patients living in an urban setting reported problems with depression compared with rural patients ( $35 \%$ vs. $19 \%, p=0.02$; Table 4 ). This observation prompted us to investigate the incidence of self-reported depression experienced by those who migrated from rural to urban settings. We found significantly more patients reported having depression for those who migrated from rural to urban than those who remained in rural settings (50\% vs. $19 \%, p=0.04)$. Other reported secondary health conditions, including autonomic dysreflexia, deep vein thrombosis, pressure ulcer, spasticity, and urinary tract infection, were not significantly different between the rural and urban populations at 1 year in the community (Table 4 ).

\section{Discussion}

This study compared patient outcomes between the rural and urban populations with tSCI. Individuals residing in rural settings who experience a tSCI face additional challenges with environmental barriers and access to specialized healthcare, which may precipitate their moving to an urban setting. Despite this, rural patients had lower incidence of self-reported depression. Most

Table 4. Secondary Health Conditions at 1 Year IN THE COMMUNity BETWEen RuRaL and Urban Populations

\begin{tabular}{lrcc}
\hline Health conditions, n (\%) & $\begin{array}{c}\text { Rural } \\
(\mathrm{n}=65)\end{array}$ & $\begin{array}{c}\text { Urban } \\
(\mathrm{n}=273)\end{array}$ & $\mathrm{p}$ value \\
\hline Autonomic dysreflexia & $9(17.3 \%)$ & $34(13.4 \%)$ & 0.292 \\
Deep vein thrombosis & $6(11.5 \%)$ & $18(7.1 \%)$ & 0.205 \\
Depression & $10(19.2 \%)$ & $90(35.4 \%)$ & $\mathbf{0 . 0 1 5}$ \\
Pressure ulcer & $9(17.3 \%)$ & $55(21.7 \%)$ & 0.310 \\
Spasticity & $34(65.4 \%)$ & $147(57.9 \%)$ & 0.199 \\
Urinary tract infection & $23(44.2 \%)$ & $110(43.3 \%)$ & 0.511 \\
\hline
\end{tabular}

Bold $\mathrm{p}$ values denote statistical significance. health and quality-of-life outcomes, as measured by FIM, SF36v2, SCIHQ, and LiSat-11, were otherwise similar between the two populations. By 1 year in the community, $13 \%$ of patients migrated from a rural to an urban setting; these patients had a lower SF36v2 MCS and a higher incidence of self-reported depression than those who remained in a rural setting.

\section{Relation to previous literature}

Difficulties experienced by individuals living with SCI in rural areas include: getting timely general practitioner (GP) appointments, rural GP lack of experience with unique health challenges, lack of local gyms and activities, access to the few local services and shops, and lack of peer support. ${ }^{28}$ People living rurally have more frequent visits to the emergency department, ${ }^{29,30}$ which may be attributed to the limited access to rural SCI-specialized care. Recent initiatives in Ontario and Australia to improve primary care outreach in the community using interprofessional teams and education in self-care and prevention have experienced initial success in bridging mobility issues and lack of local SCI expertise due to low patient volume. ${ }^{31-33}$ These concerns have also been expressed by the Veterans Administration in the United States for all veterans with chronic health conditions, indicating the conclusions of this work apply internationally not only for SCI, but also in a wider group of individuals with higher disease and/or injury burden. ${ }^{34}$

Although many previous studies have shown that patients will generally live in a private residence more than $95 \%$ of the time, less is known about whether their residence is in a rural or urban setting, and how this may impact outcomes. ${ }^{26,28}$ The results of this study demonstrated that only $13 \%$ of patients moved from a rural to urban setting post-injury, so the majority were able to remain in a rural setting regardless of their neurological impairment, even the nearly $50 \%$ of whom had a more severe cervical injury. The slightly older population who remained in a rural setting versus those who moved to an urban setting likely reflects that the rural population in general is older than in urban areas, and that there is a higher recent population growth overall in urban $(6 \%)$ compared with rural areas (3\%). ${ }^{35}$ Compensation type did not appear to differ between those who remained and those who moved from a rural to urban setting; however, the sample size is small, and the single-payer healthcare system in Canada reduces variability in care.

Interestingly, although it was the rural population that reported more physical/structural and services/assistance barriers, which have been associated with poorer subjective physical and mental health in people with SCI, ${ }^{15}$ it was the urban population, and those moving from a rural to urban setting that reported higher rates of depression (Table 4). Its clinical significance remains to be determined as other secondary health conditions were similar between the two populations. Poorer mental health as measured by SF36v2 MCS was also observed for the individuals who moved from a rural to an urban setting than those who remained in a rural setting (Table 3) to a degree reported to be clinically relevant by others. $^{36,37}$ The sense of belonging, closeness of family, and social supports that are typical of rural Canadian communities are likely potential contributors to better mental health despite the more isolated and challenging environment. A similar pattern has been found in new mothers where the rate of postpartum depression is higher in those living in urban versus rural settings. ${ }^{37}$ An opportunity to introduce preventative interventions for depression in those identified most at risk may exist. However, we were not able to determine the severity of the self-reported depression, or if the 
development of depression occurred before or after SCI; more research is needed to determine generalizability.

\section{Implication}

The findings of this study suggest that patients will be able to return to their original geographic setting regardless of the level or severity of their injury, which is reassuring for patients during their post-injury inpatient treatment. Patients and their families have numerous questions about lifestyle modifications that are necessary as a result of tSCI, so the prospect of returning to their residence can be reassuring and uplifting for patients who have recently incurred a potentially devastating injury.

From a rehabilitation perspective, the goal for discharge is always a private residence in the home community, and this goal stands for individuals living in rural areas. The resources and home modifications required for individuals returning to the community represent a huge cost for the patient, insurance provider, and the healthcare system as a whole but are unlikely to be incurred multiple times as the majority of individuals may remain in their own homes. With the increasing awareness about the importance of accessible communities ${ }^{38}$ and the availability of emerging telehealth enabling "virtual" interactions with primary care providers in the community setting, ${ }^{31,32}$ it may be possible to reduce the environmental barriers experienced.

Similarities in patient outcomes in those living in rural versus urban settings are positive findings for both patients and healthcare providers alike. The fact that there are no differences in measures of physical health, mental health, life satisfaction, functional ability, and perceived environmental barriers related to rural versus urban setting indicates that patients can achieve similar outcomes regardless of residence. The incidence of secondary health conditions also does not differ between living setting, and both are comparable to those reported in a large national study. ${ }^{39}$ These results may also apply to other injuries and diseases, such as multiple sclerosis, that limit mobility and access to specialized healthcare.

\section{Next steps/gaps}

Further longitudinal studies of patient outcomes will elucidate how tSCI and its secondary health conditions impact perceived environmental barriers, health status, and quality of life in the longterm. Future studies will analyze RHSCIR data collected over an extended period of time after discharge to examine time trends of patient outcomes, as well as to adjust for relevant clinical factors when evaluating the impact of living setting on patient outcomes. As rurality is not unique to British Columbia, this study is applicable to other provinces and countries with similar geography; future geographic expansion of this project can enhance understanding of the impact of living setting on patient outcomes. Work is also underway to investigate additional patient outcomes such as healthcare accessibility and utilization in other rural regions in Canada. Finally, findings from this study will help inform the update of the Access to Care and Timing (ACT) simulation model for tSCI care ${ }^{40,41}$ by enriching the parameter of post-injury living setting to more accurately reflect the tSCI population.

\section{Limitations}

Tracking and following patients with tSCI can be difficult. This study uses data from RHSCIR and although RHSCIR consists of a comprehensive dataset, there are inherent limitations with these data. The incidence of secondary health conditions were obtained from a self-reported questionnaire, which can be subjected to recall bias. Following these patients on a regular basis, performing detailed neurological examinations, and obtaining the numerous data points in multiple questionnaires is challenging. Alhough our follow-up rate of $77 \%$ was higher than the expected response rate of $60 \%$ for most research, ${ }^{42}$ our sensitivity analysis showed that those who did not respond had more severe injuries than those who did, which created bias. This is not an uncommon challenge in the SCI literature. One of the more robust, well-funded, research networks examining patient outcomes for degenerative conditions of the lumbar spine is the Spine Patient Outcomes Research Trial (SPORT). The authors from this study recently published follow-up rates of $55 \%$ in the randomized group and $52 \%$ in the observational group at 8 years. ${ }^{43}$ This illustrates that following even a healthy cohort of spine patients over the long-term can be very challenging.

\section{Conclusion}

The knowledge that returning home is likely following rehabilitation after tSCI, and that health and quality-of-life outcomes will be similar regardless of place of residence, is positive information for individuals after a life-changing injury. Future efforts should ensure individuals with tSCI are screened for mental health problems such as depression and anxiety throughout the care continuum for early detection, and are treated and followed up in the community.

\section{Acknowledgments}

The authors thank all RHSCIR participants for their time and effort in the follow-up questionnaire and for being part of the RHSCIR research study; the Vancouver Spine Research Program (Allan Aludino); the Rick Hansen Institute RHSCIR team (Suzanne Humphreys, Daniel Rogers, Kristen Walden, Jayson Shurgold, Jessica Eapen, Jerome Buenaventura, Tova Plashkes, Arlene Aspinall, Cynthia Morin, and Shannon Sproule); and all members of the Vancouver Spine Surgery Institute for their support with the study.

FIM $^{\circledR}$ is a trademark of the Uniform Data System for Medical Rehabilitation, a division of UB Foundation Activities, Inc.

SF-36v2 ${ }^{\circledR}$ Health Survey (C) 1992-2002 Medical Outcomes Trust and QualityMetric Incorporated. All rights reserved. SF-36 ${ }^{\circledR}$ is a registered trademark of Medical Outcomes Trust.

\section{Author Disclosure Statement}

This study was supported by financial contributions from the Rick Hansen Institute, the Ontario Neurotrauma Foundation, and the Government of Canada through Health Canada and Western Economic Diversification Canada.

\section{References}

1. Noonan, V.K., Fingas, M., Farry, A., Baxter, D., Singh, A., Fehlings, M.G., and Dvorak, M.F. (2012). Incidence and prevalence of spinal cord injury in Canada: a national perspective. Neuroepidemiology 38, 219-226.

2. Burrows, S., Auger, N., Gamache, P., and Hamel, D. (2013). Leading causes of unintentional injury and suicide mortality in Canadian adults across the urban-rural continuum. Public Health Rep. 128, 443-453.

3. Moazzami, B. (2015). Strengthening rural Canada: fewer \& older: the population and demographic dilemma in rural British Columbia. Government of Canada: Ottawa, ON.

4. Canadian Institute for Health Information. (2006). How healthy are rural Canadians? An assessment of their health status and health determinants. Ottawa, ON. 
5. Sorocco, K.H., Bratkovich, K.L., Wingo, R., Qureshi, S.M., and Mason, P.J. (2013). Integrating care coordination home telehealth and home based primary care in rural Oklahoma: a pilot study. Psychol. Serv. 10, 350-352.

6. Jackson, B., Coultas, M., Suzuki, S., Singh, K., and Bae, S. (2013). Rural-urban disparities in quality of life among patients with COPD. J. Rural Health 29, 1199-1216.

7. Kurpas, D., Mroczek, B., and Bielska, D. (2014). Rural and urban disparities in quality of life and health-related behaviors among chronically ill patients. Rural Remote Health 14, 2485.

8. Vervoordeldonk, J.J., Post, M.W., New, P., and Van Asbeck, F.W. (2013). Rehabilitation of patients with nontraumatic spinal cord injury in the Netherlands: etiology, length of stay, and functional outcome. Top. Spinal Cord Inj. Rehabil. 19, 195-201.

9. Walters, B.C., Hadley, M.N., Hurlbert, R.J., Aarabi, B., Dhall, S.S., Gelb, D.E., Harrigan, M.R., Rozelle, C.J., Ryken, T.C., and Theodore, N. (2013). Guidelines for the management of acute cervical spine and spinal cord injuries: 2013 update. Neurosurgery 60, 82-91.

10. Evans, L.T., Lollis, S.S., and Ball, P.A. (2013). Management of acute spinal cord injury in the neurocritical care unit. Neurosurg. Clin. North Am. 24, 339-347.

11. Kennedy, P., Sherlock, O., McClelland, M., Short, D., Royle, J., and Wilson, C. (2010). A multi-centre study of the community needs of people with spinal cord injuries: the first 18 months. Spinal Cord 48, 15-20.

12. Bloemen-Vrencken, J.H., de Witte, L.P., and Post, M.W. (2005) Follow-up care for persons with spinal cord injury living in the community: a systematic review of interventions and their evaluation. Spinal Cord 43, 462-475.

13. Dryden, D.M., Saunders, L.D., Rowe, B.H., May, L., Yiannakoulias, N., Svenson, L.W., Schopflocher, D.P., and Voaklander, D.C. (2004). Utilization of health services following spinal cord injury: a 6-year follow-up study. Spinal Cord 42, 513-525.

14. DeJong, G., Tian, W., Hsieh, C.H., Junn, C., Karam, C., Ballard, P.H., Smout, R.J., Horn, S.D., Zanca, J.M., Heinemann, A.W., Hammond, F.M., and Backus, D. (2013). Rehospitalization in the first year of traumatic spinal cord injury after discharge from medical rehabilitation. Arch. Phys. Med. Rehabil. 94, S87-S97.

15. Cao, Y., Walker, E.A., and Krause, J.S. (2015). Environmental barriers and subjective health among people with chronic spinal cord injury: a cohort study. J. Spinal Cord Med. 38, 526-531.

16. Noreau, L., Fougeyrollas, P., and Boschen, K. (2002). Perceived influence of the environment on social participation among individuals with spinal cord injury. Top. Spinal Cord Inj. Rehabil. 7, 56-72.

17. Whiteneck, G., Meade, M.A., Dijkers, M., Tate, D.G., Bushnik, T., and Forchheimer, M.B. (2004). Environmental factors and their role in participation and life satisfaction after spinal cord injury. Arch. Phys. Med. Rehabil. 85, 1793-1803.

18. Noonan, V.K., Kwon, B.K., Soril, L., Fehlings, M.G., Hurlbert, R.J., Townson, A., Johnson, M., and Dvorak, M.F. (2012). The Rick Hansen Spinal Cord Injury Registry (RHSCIR): a national patientregistry. Spinal Cord 50, 22-27.

19. Noreau, L., Cobb, J., Bélanger, L.M., Dvorak, M.F., Leblond, J., and Noonan, V.K. (2013). Development and assessment of a community follow-up questionnaire for the Rick Hansen Spinal Cord Injury Registry. Arch. Phys. Med. Rehabil. 94, 1753-1765.

20. Waring, W.P., Biering-Sorensen, F., Burns, S., Donovan, W., Graves, D., Jha, A., Jones, L., Kirshblum, S., Marino, R., Mulcahey, M.J., Reeves, R., Scelza, W.M., Schmidt-Read, M., and Stein, A. (2010). 2009 review and revisions of the International Standards for the Neurological Classification of Spinal Cord Injury. J. Spinal Cord Med. 33, 346-352.

21. Hart, L.G., Larson, E.H., and Lishner, D.M. (2005). Rural definitions for health policy and research. Am. J. Public Health 95, 1149-1155.

22. Whiteneck, G., Harrison-Felix, C., Mellick, D., Brooks, C., Charlifue, S., and Gerhart, K. (2004). Quantifying environmental factors: a measure of physical, attitudinal, service, productivity, and policy barriers. Arch. Phys. Med. Rehabil. 85, 1324-1335.

23. Ware, J. (2007). User's Manual for the SF36v2 Health Survey, 3rd ed. Quality Metric, Inc.: Lincoln, RI.

24. Fugl-Meyer, A.R., Branholm, I.B., and Fugl-Meyer, K.S. (1991). Happiness and domain-specific life satisfaction in adult northern Swedes. Clin. Rehabil. 5, 25-33.

25. Keith, R.A., Granger, C. V, Hamilton, B.B., and Sherwin, F.S. (1987). The functional independence measure: a new tool for rehabilitation. Adv. Clin. Rehabil. 1, 6-18.
26. Andresen, E.M., Fouts, B.S., Romeis, J.C., and Brownson, C.A (1999). Performance of health-related quality-of-life instruments in a spinal cord injured population. Arch. Phys. Med. Rehabil. 80, 877884.

27. Post, M., and Noreau, L. (2005). Quality of life after spinal cord injury. J. Neurol. Phys. Ther. 29, 139-146.

28. Goodridge, D., Rogers, M., Klassen, L., Jeffery, B., Knox, K., Rohatinsky, N., and Linassi, G. (2015). Access to health and support services: perspectives of people living with a long-term traumatic spinal cord injury in rural and urban areas. Disabil. Rehabil. 37, 14011410.

29. Guilcher, S.J., Munce, S.E., Couris, C.M., Fung, K., Craven, B.C., Verrier, M., and Jaglal, S.B. (2010). Health care utilization in nontraumatic and traumatic spinal cord injury: a population-based study. Spinal Cord 48, 45-50.

30. Munce, S.E., Guilcher, S.J., Couris, C.M., Fung, K., Craven, B.C., Verrier, M., and Jaglal, S.B. (2009). Physician utilization among adults with traumatic spinal cord injury in Ontario: a population-based study. Spinal Cord 47, 470-476.

31. van de Pol, E., Lucas, K., Geraghty, T., Pershouse, K., Harding, S., Atresh, S., Wagemakers, A., and Smith, A.C. (2016). The delivery of specialist spinal cord injury services in Queensland and the potential for telehealth. BMC Health Serv. Res. 16, 29.

32. Milligan, J., and Lee, J. (2016). Enhancing primary care for persons with spinal cord injury: more than improving physical accessibility. J. Spinal Cord Med. 39, 496-499.

33. Spinal Outreach Team. (2016). Spinal Outreach Team Newsletter. Brisbane, QLD: Queensland Spinal Cord Injury Service.

34. Hamilton, B.A. (2008). Veterans rural health: perspectives and opportunities. Rockville, MD: Veterans Health Administration.

35. Rothwell, N., Bollman, R.D., Tremblay, J., and Marshall, J. (2002) Recent migration patterns in rural and small town Canada. Ottawa, $\mathrm{ON}$ : Ministrer of Industry.

36. Ware, J., Snow, K., Kosinski, M., and Gandek, B. (1993). SF-36 Health Survey: manual and interpretation guide. Boston, MA: The Health Institute, New England Medical Center.

37. Vigod, S., Tarasoff, L., Bryja, B., Dennis, C.L., Yudin, M., and Ross, L. (2013). Relation between place of residence and postpartum depression. CMAJ 185, 1129-1135.

38. Rick Hansen Foundation. (2016). Introducing The Global Access and Inclusion Hub. Available at: http://www.rickhansen.com/Blog/ArtMID/ 13094/ArticleID/123/Introducing-The-Global-Access-Inclusion-Hub. Accessed August 11, 2016.

39. Noreau, L., Noonan, V.K., Cobb, J., Leblond, J., and Dumont, F.S. (2014). Spinal cord injury community survey: a national, comprehensive study to portray the lives of Canadians with spinal cord injury. Top. Spinal Cord Inj. Rehabil. 20, 249-264.

40. Santos, A., Gurling, J., Dvorak, M.F., Noonan, V.K., Fehlings, M.G. Burns, A.S., Lewis, R., Soril, L., Fallah, N., Street, J.T., Bélanger, L. Townson, A., Liang, L., and Atkins, D. (2013). Modeling the patient journey from injury to community reintegration for persons with acute traumatic spinal cord injury in a Canadian centre. PLoS One 8 , e72552.

41. Noonan, V.K., Soril, L., Atkins, D., Lewis, R., Santos, A., Fehlings, M.G., Burns, A.S., Singh, A., and Dvorak, M.F. (2012). The application of operations research methodologies to the delivery of care model for traumatic spinal cord injury: the access to care and timing project. J. Neurotrauma 29, 2272-2282.

42. Fincham, J.E. (2008). Response rates and responsiveness for surveys, standards, and the journal. Am. J. Pharm. Educ. 72, 43.

43. Lurie, J.D., Tosteson, T.D., Tosteson, A., Abdu, W., Zhao, W., Morgan, T.S., and Weinstein, J.N. (2015). Long-term outcomes of lumbar spinal stenosis. Spine 40, 63-76.

Address correspondence to:

R. Andrew Glennie, MD

Department of Surgery

Dalhousie University

1796 Summer Street, Room 4558

Halifax, Nova Scotia

Canada

E-mail: andrew_glennie@hotmail.com 